\title{
Role of Economic Policy Uncertainty in the Connectedness of Cross-Country Stock Market Volatilities
}

\author{
Mudassar Hasan ${ }^{1}\left(\mathbb{D}\right.$, Muhammad Abubakr Naeem ${ }^{2,3}{ }^{(D}$, Muhammad Arif ${ }^{4}(\mathbb{D}$, \\ Syed Jawad Hussain Shahzad $5,6, * \mathbb{D}$ and Safwan Mohd Nor ${ }^{7,8}$ (D) \\ 1 Lahore Business School, the University of Lahore, Lahore 54000, Pakistan; mudassar.hassan@lbs.uol.edu.pk \\ 2 School of Economics and Finance, Massey University, Palmerston North 4442, New Zealand; \\ m.naeem@massey.ac.nz \\ 3 Business Administration Department, Faculty of Management Sciences, ILMA University, \\ Karachi 75190, Pakistan \\ 4 Department of Business Administration, Shaheed Benazir Bhutto University, \\ Shaheed Benazirabad 67450, Pakistan; marif@sbbusba.edu.pk \\ 5 Finance, Control and Law Department, Montpellier Business School, 34080 Montpellier, France \\ 6 Department of Accounting, Analysis and Audit, South Ural State University, Chelyabinsk 454080, Russia \\ 7 Faculty of Business, Economics and Social Development, University of Malaysia Terengganu, \\ 21030 Kuala Nerus, Terengganu, Malaysia; safwan@umt.edu.my \\ 8 Victoria Institute of Strategic Economic Studies, Victoria University, Melbourne, Victoria 3000, Australia \\ * Correspondence: j.syed@montpellier-bs.com
}

Received: 4 September 2020; Accepted: 21 October 2020; Published: 31 October 2020

\begin{abstract}
The implied volatility index is a forward-looking indicator of fear among stock market participants. We examine the extent to which the connectedness of fear among global stock markets is driven by the cross-country connectedness of economic policy uncertainty (EPU). We use data on stock market fear and EPU indices for 13 countries, which spans from January 2011 to December 2018. To measure the connectedness among stock market fear and EPU of our sample countries, we employ two connectedness models. A cross-sectional regression model is further employed to ascertain the extent to which EPU connectedness between two countries explains the connectedness of fear between their stock markets, while controlling for bilateral linkage and country-specific factors. We find that EPU connectedness between any two partner countries significantly drives the connectedness of fear between their stock markets. The driving potential not only holds for short- and long-term connectedness, but also after controlling for bilateral linkages (bilateral trade, geographical distance, common language) and country-specific (trade and financial openness of the transmitter country) factors indicating robustness in our results.
\end{abstract}

Keywords: fear connectedness; economic policy uncertainty; stock markets; bilateral linkages

JEL Classification: C58; G15; F42

\section{Introduction}

For international market investors and policymakers, understanding the connectedness of implied volatility (fear) is critical to make equity and derivative pricing decisions, as well as to devise hedging and risk management strategies. The volatility or fear has previously been computed either from a model, such as generalized auto-regressive heteroskedasticity-GARCH [1], or from historical returns [2]. Those latent indicators of realized volatility often fail to capture the fear that is anticipated among stock 
market participants. As well as improving the understanding of cross-country fear propagation [3,4], this understanding also deepens investor's knowledge on the underpinnings of the market integration phenomenon, which has become increasingly prevalent in the aftermath of the global financial crisis (hereafter GFC). In this vein, the seminal work of Pastor and Veronesi [5] laid out theoretical foundations for the potential effects of economic policy uncertainty (hereafter EPU) on stock returns and volatility. Subsequently, a growing number of scholars began to investigate the transmission of fear across the country or regional stock markets [6,7]. However, the literature on the driving potential of EPU connectedness for fear connectedness remains scant.

On a domestic front, EPU leads to increased stock market fear via investor sentiment when economic policies are hard to anticipate among market participants. Higher uncertainty around economic policies also raises stock market fear through the stochastic discount factor, which shoots up risk premia and thereby fear in stock markets [5]. Given the increased levels of economic and financial integration, however, the domestic EPU shocks are not just restricted to the source country, but rather spillover across borders [8], which could amplify the cross-country transmission of fear (other studies that examine the cross-country spillovers of EPU include Yin and Han [9] and Kang and Yoon [10]). Accordingly, Liow et al. [11] suggest that the dynamic connectedness of EPU across major economies leads to stress spillovers among their financial markets. However, their research focuses primarily on the interaction between financial markets' spillovers and those of the EPU. We go one step further by breaking down the network-based analysis into a pairwise setting and thereby explore how EPU spillovers between a pair of countries explain the fear spillovers between their stock markets. In addition, while analysis only includes G7 countries and thus offers a regional perspective, by selecting a broad range of countries from both developed and emerging markets, we provide a global perspective on the EPU-stock market linkage. Lastly, they rely on GARCH-based volatility measure to estimate the spillovers of financial stress across G7 markets, whereas we use the forward-looking, implied-volatility indices, which provide a better predictive value for volatility transmission. The Chicago Board Options Exchange (CBOE) developed the implied volatility (VIX) index from the two concept papers [12,13]. The index is obtained from option markets and are widely considered as proxy for stock market fear. Following the same concept, the implied volatility indices for other countries have been developed as well. We are primarily interested in the connectedness among these fear indices, and the extent to which this connectedness is driven by EPU connectedness. Thus, the procedure (methods) used to estimate these indices do not fall under the scope of this research. In this regard, economic and financial linkages are two possible channels through which policy uncertainty shocks transmit to foreign asset markets [14,15].

We first use the connectedness model of Diebold and Yilmaz [16] (hereafter DY) and Baruník and Křehlík [17] (hereafter BK) to measure the time and frequency connectedness of fear as well as of EPU among our sample countries. Second, we employ a cross-sectional regression model, to ascertain the extent to which EPU connectedness between two countries explains the connectedness of fear between their stock markets. Finally, we add bilateral linkage and country-specific factors as control variables to test the robustness of our estimations.

We find that the stock market fear connectedness across our sample countries is much stronger compared to the EPU connectedness between them. When decomposed, the fear connectedness in the short-term is found to be remarkably higher than the long-term counterparts. The US, Germany, and China are found to be the highest transmitters of fear shocks while the most prominent recipients of those shocks are Japan, South Korea, and Hong Kong. Relative to markets in North America and Asia, European stock markets are more connected in regard to their fear shocks, pointing to the presence of geographic heterogeneity in fear connectedness. Finally, EPU connectedness between any two partner countries is a strong driver of fear connectedness between their stock markets. The driving impact of EPU connectedness not only persists for short-and long-term connectedness, but also after accounting for bilateral linkages (bilateral trade, geographical distance, common language) and 
country-specific (transmitter country trade and financial openness) factors indicating our results are robust to different specifications.

The remainder of this study unfolds as follows. Section 2 includes a brief discussion on theoretical issues and the advancements made by this study. Section 3 provides details on data and methodology. Section 4 offers empirical findings. Section 5 concludes.

\section{The Theoretical Issues}

In the section, we provide an overview of the past literature related to this study and the theoretical issues that this study aims to address.

The first strand of literature includes studies that explore the cross-market linkages of implied volatility or fear across countries and regions using spillover network framework. Äijö [18] examines the implied volatility term structure linkages between the volatility indices for the German, the Swiss, and the EURO STOXX 50 markets. The study demonstrates that the estimated volatility term structures are highly correlated, indicating that they are closely linked to each other. Bouri et al. [3] suggest that individual implied volatilities in BRICS countries are linked to both global and within the group stock market implied volatilities and that the role of commodity market volatility is marginal, except for South Africa. Similarly, Tsai [19] investigated the spillover network of implied volatility among the US, the UK, Germany, Japan, and France, finding that information transmission between these stock markets increases considerably after 1998, with Germany and the US being the main stock markets conveying information to other international markets. Badshah [6] examines cross-market volatility linkages among implied volatility indices of the US, the developed-markets, and the emerging-markets, confirming the dominant role of the US index. Chen [20] analysed fear spillover network among implied volatility indices of Canada, Japan, Germany, and the US. Using a copula-based bivariate Markov-switching model, the authors provide a strong evidence of dependencies, contagion, and causalities between the four implied volatility indices. Shu and Chang [21] investigated the cross-market interaction between implied volatility indices of the US, the Europe, and South Korean, and stock returns of the US and non-US markets. The authors found that the pervasive influence of VIX on both US and non-US stock markets. The cross-market spillovers of implied volatility indicate the US as the primary transmitter, and the as the leading receiver, of these spillovers, pointing to a leading role for the VIX in the international market. BenSaïda et al. [7] investigated spillover across volatility indices of eight developed financial stock markets and found that the total and directional spillovers are more intense during turbulent periods, with frequent swings between net risk transmission and net risk reception. During the tranquil periods, however, the volatility spillovers are relatively moderate.

A second strand of literature explores the network structure of EPU. With the introduction of EPU index by Baker et al. [22] for the US, researcher started creating EPU indices for other countries. This enabled academic community to investigate the spillover network of EPU across various countries. In this vein, several studies have examined the cross-country network dynamics of EPU, including [8-10,23-25]. However, there is a lack of clarity about the relationship that EPU network may have with other network structures.

In this regard, few efforts have been made that constitute a third strand of literature. Such works try to link EPU network or EPU with the volatility networks formed by either asset markets of major economies or global stock markets. Liow et al. [11], for instance, examine the causality between volatility spillovers in asset markets, including stocks, bonds, real estate, and currency markets, and the EPU spillovers across G7 nations, finding that a substantial amount of EPU and financial market volatility can be attributed to spillover effects coming from abroad. Within a multi-country setting, the study suggests that EPU spillovers cause volatility spillovers in G7 financial markets, indicating that changes in EPU spillovers can predict changes in financial market risk spillovers in the short-run. Similarly, Tsai [26] explored the effect of EPU in four countries or regions, namely China, Japan, Europe, and the United States, on the contagion risk in the global stock markets. The author suggests Chinese EPU is the predominant driver of contagion risk in different regional stock markets. Japanese EPU 
causes contagion risk in emerging markets only, while the contagion risk in European equity markets is vulnerable to none of the EPU indices.

Overall, the abovementioned literature has the following theoretical issues that needs to be addressed. The first strand of literature shows that stock market fear or volatility is significantly interconnected across global stock markets, and is often dominated by regional heavy weights such as the US. Most studies supporting this notion focus on the fear interrelationships across different markets at the regional level. While such country- or regional-wise analyses have their uses for certain types of market participants, they provide little knowledge to the investors who are concerned with transmission of fear on a global scale. This study is an attempt towards this direction. By considering 13 implied volatility indices, this study provides a global evidence on the transmission of stock market fear. Another important issue relates to incomplete understanding of the fear connectedness phenomenon. While previous studies shed sufficient light on how the spillover network of stock market fear behaves, what remains unclear is the factors that drive this network. This study explains the spillovers of fear from one country to another by using bilateral linkages, country-specific factors, and, more importantly, EPU spillovers. The significance of this contribution can be understood from the fact that a reasonable explanation of fear propagation between countries is a critical factor for forecasting the trajectory of investor sentiment [3].

Mathematically, this study contributes by introducing a relationship between EPU network and fear network. More precisely, the study shows the extent to which the connections between nodes of EPU network explain those between nodes of fear network. Going beyond the overall network-based relationships between spillovers of EPU and stock market volatility, this study breaks down these network interactions into individual nodes. This contribution is built upon and is closely related to [26] who documents several examples of policy related events that drive short-term responses from stock markets around the world. It is also built upon [11] who suggest that the dynamic connectedness of EPU across major economies leads to stress spillovers among their financial markets. However, their research focuses primarily on the interaction between financial markets' spillovers and those of the EPU. We go one step further by breaking down the network-based analysis into pairwise setting.

\section{Data and Methodology}

We consider monthly EPU series of 13 countries from the economic policy uncertainty website (http://www.policyuncertainty.com), respectively, over a period from January 2011 to December 2018. The EPU index used in this study is created by Baker et al. [22] through an analysis of newspaper articles containing terms related to economic policy uncertainty. For this purpose, they select 10 large newspapers (USA Today, the Miami Herald, the Chicago Tribune, the Washington Post, the Los Angeles Times, the Boston Globe, the San Francisco Chronicle, the Dallas Morning News, the Houston Chronicle, and the WSJ). To construct the index, the authors performed monthly searches of each paper for terms related to economic and policy uncertainty. In particular, they search for articles containing the term 'uncertainty' or 'uncertain', the terms 'economic' or 'economy' and one or more of the following terms: 'congress', 'legislation', 'white house', 'regulation', 'federal reserve', or 'deficit'. The article counts are further scaled, standardized, and normalized with a mean of 100 to obtain the final index over a period from January 1985 to the present. Following the same method, the EPU indices for several other countries have been created.

The daily fear indices for the same 13 countries have been collected from Thomson Reuters Datastream International. The data period and sample countries are selected purely based on data availability. Data on bilateral trade and trade openness came from IMF's database and World Development Indicators, respectively. Data on geographical distances, geographical proximity, colonial ties, and common language are obtained from the French Research Center in International Economics. We also use the financial openness index of Chinn and Ito [27], downloaded from their website (http://web.pdx.edu/ ito/Chinn-Ito_website.htm). Table A1 in Appendix A provides details of the data and their sources. 


\subsection{The Connectedness Model}

Our methodology consists of two parts. First, we compute total spillovers among fear (EPU) series begin by applying the DY and BK framework to estimate the time and frequency connectedness of fear among our sample countries. The BK methodology helps account for the possible heterogeneity around the connectedness of fear shocks. Since financial investors operate at different time horizons, the interactions among their expectations may well vary for short- and long-terms. In our case, the frequency bands correspond to movements over 1-22 days (one month) and 23-250 days (one year), representing short- and long-term dynamics of fear connectedness, respectively. Because our EPU indices are monthly series, the choice of 1-22 days (one month) to capture the short-term frequency dynamics is made to match the monthly connectedness dynamics of the EPU.

We begin by applying the Diebold and Yilmaz [16] model to measure the fear connectedness in a generalized VAR framework of Pesaran and Shin [28]. Consider a covariance stationary $N$-variable VAR $(p), x_{t}=\sum_{i=1}^{p} \phi_{i} x_{t-i}+\varepsilon_{t}$, where $x_{i}$ is the $N \times 1$ vector of the endogenous variables (log-differenced series of fear indexes), $\varepsilon_{t} \sim(0, \Sigma)$ is a vector of independently and identically distributed disturbances. The connectedness can be defined by the $H$-step-ahead generalized forecast error variance decomposition which is given by:

$$
\theta_{i j}(H)=\frac{\sigma_{j j}^{-1} \sum_{h=0}^{H-1}\left(e_{i}^{\prime} A_{h} \Sigma e_{j}\right)^{2}}{\sum_{h=0}^{H-1}\left(e_{i}^{\prime} A_{h} \Sigma A_{h}^{\prime} e_{i}\right)}
$$

where $\Sigma$ is the variance matrix containing a vector of errors, $\sigma_{j j}$ is the standard deviation of the error term of the $j$ th equation, and $e_{i}$ is a selection vector with a value of one for the $i$ th element and zero otherwise. The pairwise fear connectedness from county $j$ to country $i$ is given by the variance decomposition matrix as follows:

$$
\widetilde{\theta}_{i j}(H)=\frac{\theta_{i j}(H)}{\sum_{j=1}^{N} \theta_{i j}(H)}
$$

The net pairwise connectedness $\left(N P C_{i j}\right)$, given below, is simply the difference between the gross shocks transmitted from Fear $i$ to Fear $j$ and those transmitted from $j$ to $i$ and $\widetilde{\theta}_{i j}(H)=\frac{\theta_{i j}(H)}{\sum_{j=1}^{N} \theta_{i j}(H)}$ is the variance decomposition matrix.

$$
N P C_{i j}(H)=\left(\frac{\widetilde{\theta}_{j i}(H)}{\sum_{i, k=1}^{N} \widetilde{\theta}_{i k}(H)}-\frac{\widetilde{\theta}_{i j}(H)}{\sum_{j, k=1}^{N} \widetilde{\theta}_{j k}(H)}\right) \times 100
$$

To account for the possibility of heterogeneity around the connectedness of fear shocks, we apply the framework recently introduced by Baruník and Křehlík [17], which enables us to disaggregate the connectedness of fear over the short-, medium-, and long-term horizons. Accordingly, at a given frequency $\omega, \widetilde{\theta}_{j i}(\omega)$ denotes the share of the spectrum of the country $i$ that can be attributed to shocks in the country $j$ and thus the time domain counterpart of Equation (2) can be written as:

$$
\widetilde{\theta}_{i j}(\omega)=\frac{\theta_{i j}(\omega)}{\sum_{h=1}^{n} \theta_{i j}(\omega)} .
$$

In this setting, the accumulative connectedness at an arbitrary frequency band $d=(a, b)$ can be obtained as:

$$
\widetilde{\theta}_{i j}(d)=\int_{a}^{b} \widetilde{\theta}_{i j}(\omega) d \omega
$$


Accordingly, at a given frequency band $d$, the net pairwise connectedness from country $i$ to country $j$ can be computed as:

$$
N P C_{i j}(d)=\widetilde{\theta}_{j i}(d)-\widetilde{\theta}_{i j}(d)
$$

\subsection{The Cross-Country Determinants of Fear Connectedness}

Finally, to explore the determinants of the cross-country fear connectedness, we posit that the connectedness of fear between country $i$ and country $j$ is explained by the following crosssectional regression:

$$
N P C_{i j}=\alpha_{o}+\alpha_{1} E P U_{i j}+\epsilon_{i j}
$$

where $N P C_{i j}$ is the net pairwise spillover of fear from country $i$ to country $j, E P U_{i j}$ is EPU spillover from country $i$ to country $j$. Using EPU connectedness to explain fear connectedness, especially within the context of heightened economic and financial integration, calls for other relevant factors to be accounted for as well. In this context, the literature broadly classifies such factors into two categories: bilateral linkages and country-specific features that can explain the interactions between stock market shocks. Bilateral linkages include trade and financial linkages [29]; geographical distance, and common language [30]; and colonial ties [31]. Country-specific factors include trade and financial openness of a country that plays a vital role in the transmission/reception of shocks [32]. To ensure the robustness of our results, we first control for bilateral linkage as given below:

$$
\begin{aligned}
N P C_{i j}=\alpha_{0}+ & \alpha_{1} E P U_{i j}+\alpha_{2} \text { Contig }_{i j}+\alpha_{3} \operatorname{Col}_{i j}+\alpha_{4} \text { Common_Lang }_{i j}+\alpha_{5} \log \left(\text { Dist }_{i j}\right) \\
& \left.+\alpha_{6} \log _{\text {Lrade }}\right)+\epsilon_{i j}
\end{aligned}
$$

where Contig $g_{i j}, \mathrm{Col}_{i j}$, and Common_Lang ${ }_{i j}$, and Trade $_{i j}$ are the dummy variables representing geographical proximity, colonial ties, and common language, and physical distance and bilateral trade between the two countries, respectively. Additionally, we control for country-specific factors, as follows:

$$
\begin{aligned}
\mathrm{NPC}_{i j}=\alpha_{o}+ & \alpha_{1} \mathrm{EPU}_{i j}+\alpha_{2} \text { Contig }_{i j}+\alpha_{3} \text { Col }_{i j}+\alpha_{4} \text { Common_Lang }_{i j}+\alpha_{5} \log \left(\text { Dist }_{i j}\right) \\
& \left.+\alpha_{6} \text { Log }_{\text {Trade }} \text { (Tij }\right)+\alpha_{7} \text { Trade_Open }_{i}+\alpha_{8} \text { Trade_Open }_{j} \\
& +\alpha_{9} \text { Fin_Open }_{i}+\alpha_{10} \text { Fin_Open }_{j}+\epsilon_{i j}
\end{aligned}
$$

where Trade_Open $\left(\right.$ Fin_Open $\left._{i}\right)$ and Trade_Open ${ }_{j}\left(\right.$ Fin_Open $\left._{j}\right)$ represent trade (financial) openness of country $i$ and country $j$, respectively.

\section{Empirical Findings}

We transform the pairwise estimates of both fear and EPU connectedness into bar charts and present them in Figures 1-4 for a clear representation of the results. Figures 1-3 correspond to the connectedness estimates given in panels A to C (of Table A2 in the Appendix A), respectively, while Figure 4 represents those shown in Table A3. The height of a bar indicates the overall spillover of fear (EPU) that a country sends to all other countries, with colored sections reflecting the share of spillover that a partner country receives from a source country. The average height of the bars indicates the total connectedness of the whole system.

Note that the average height of the bars is the highest in Figure 1, which indicates that the total connectedness across our sample countries is quite substantial. In order to ascertain the exact magnitude of the total connectedness, however, we will refer to the Table A2 (panel A); where we precisely see that $67.21 \%$ of the total spillover of fear across our sample countries is attributed to the shocks across them, while idiosyncratic (country-specific) fear shocks explain the remainder of the spillovers. The total connectedness is further divided into short- and long-term components, shown, respectively, in Figures 2 and 3. On average, the bars in Figure 1 are much taller than those in Figure 2. The magnitudes of the short-term connectedness are significantly higher than the long-term 
connectedness, suggesting that short-term sentiments of market participants are much more contagious compared to the long-term. The intuition behind this finding is that the implied-volatility indices are driven primarily from market participants' short-term expectations about the future [33]. Hence, one would expect the connectedness of fear to be more pronounced in the short-term.

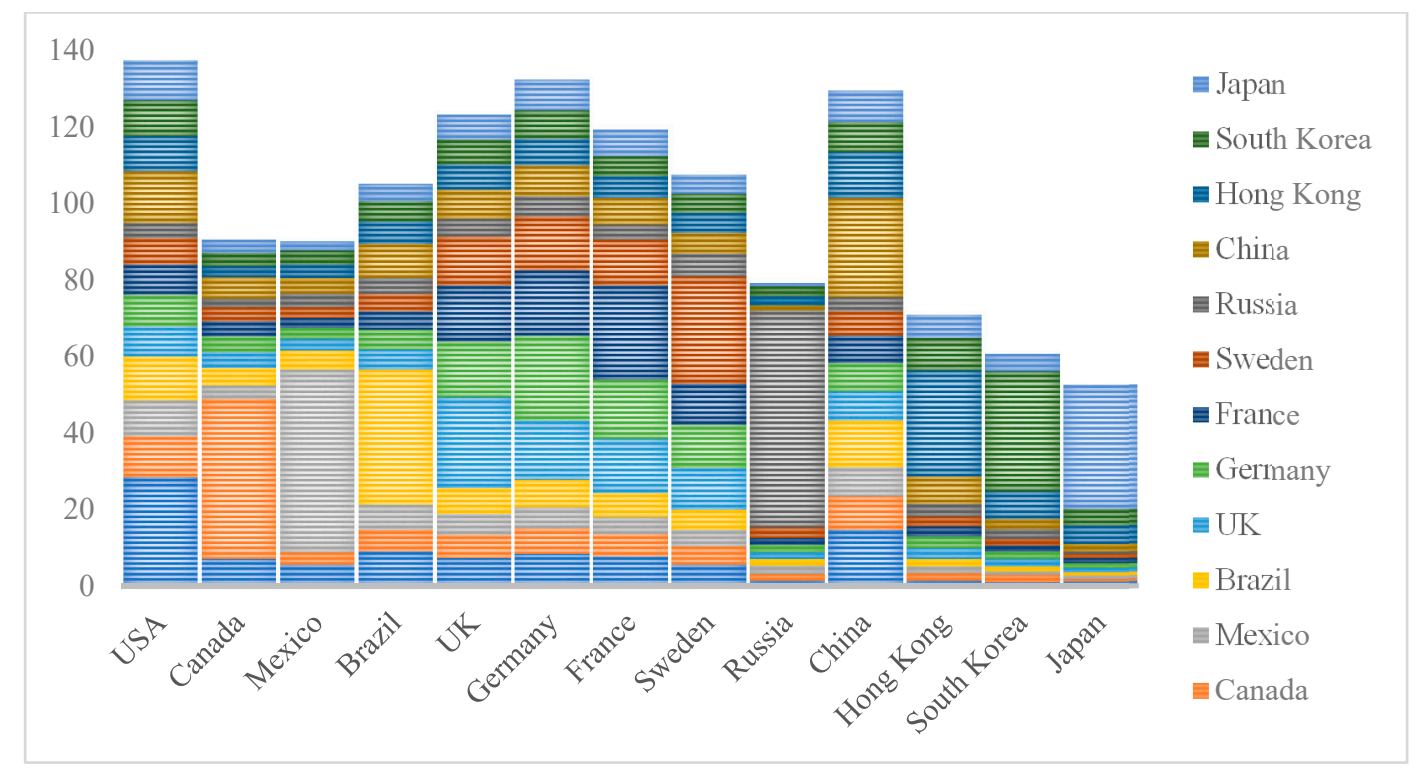

Figure 1. Total connectedness.

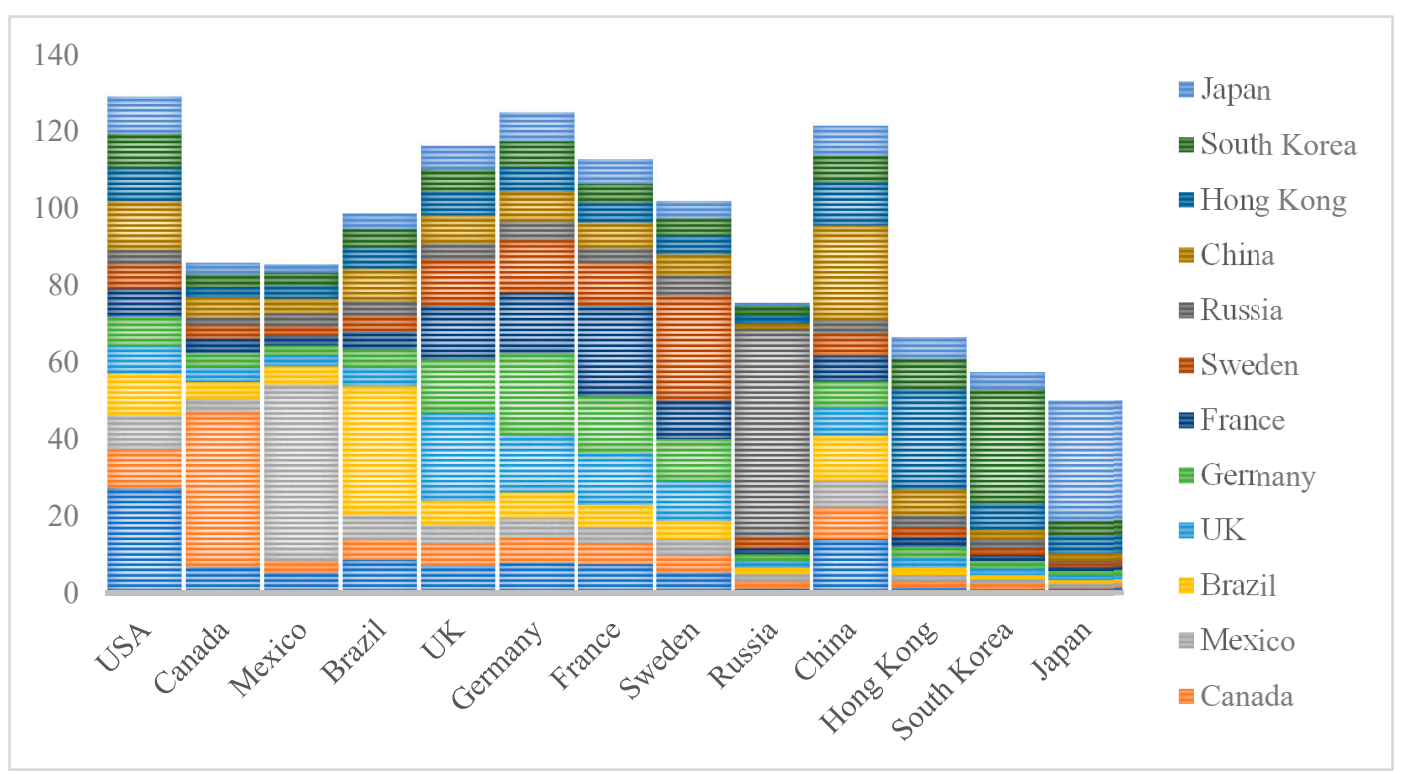

Figure 2. Short-term connectedness.

Compared to the fear connectedness across our sample countries, we find that the colored sections representing the country's own share of spillovers are higher for EPU connectedness (see Figure 4). This suggests that the fear in stock markets is far more contagious than the uncertainty surrounding economic policy. This finding corroborates previous literature, such as [8-10], suggesting that EPU dynamics are driven more by own-country's EPU spillovers and less by system-wide spillovers. Maybe it is because the stock markets around the world are much more integrated [34] than the economic policies. Nonetheless, global initiatives are being taken across the Organization for Economic Co-operation and Development (OECD) countries to accomplish policy coherence. To this end, see the 'Policy coherence for sustainable development goals', which is an ongoing initiative of the OECD. 
Additionally, the price movements in stock markets are largely governed by global participants whose expectations of market uncertainty seem to spread far more sporadically than the economic policy that is more the result of slow-moving political regimes and prolonged business cycles.

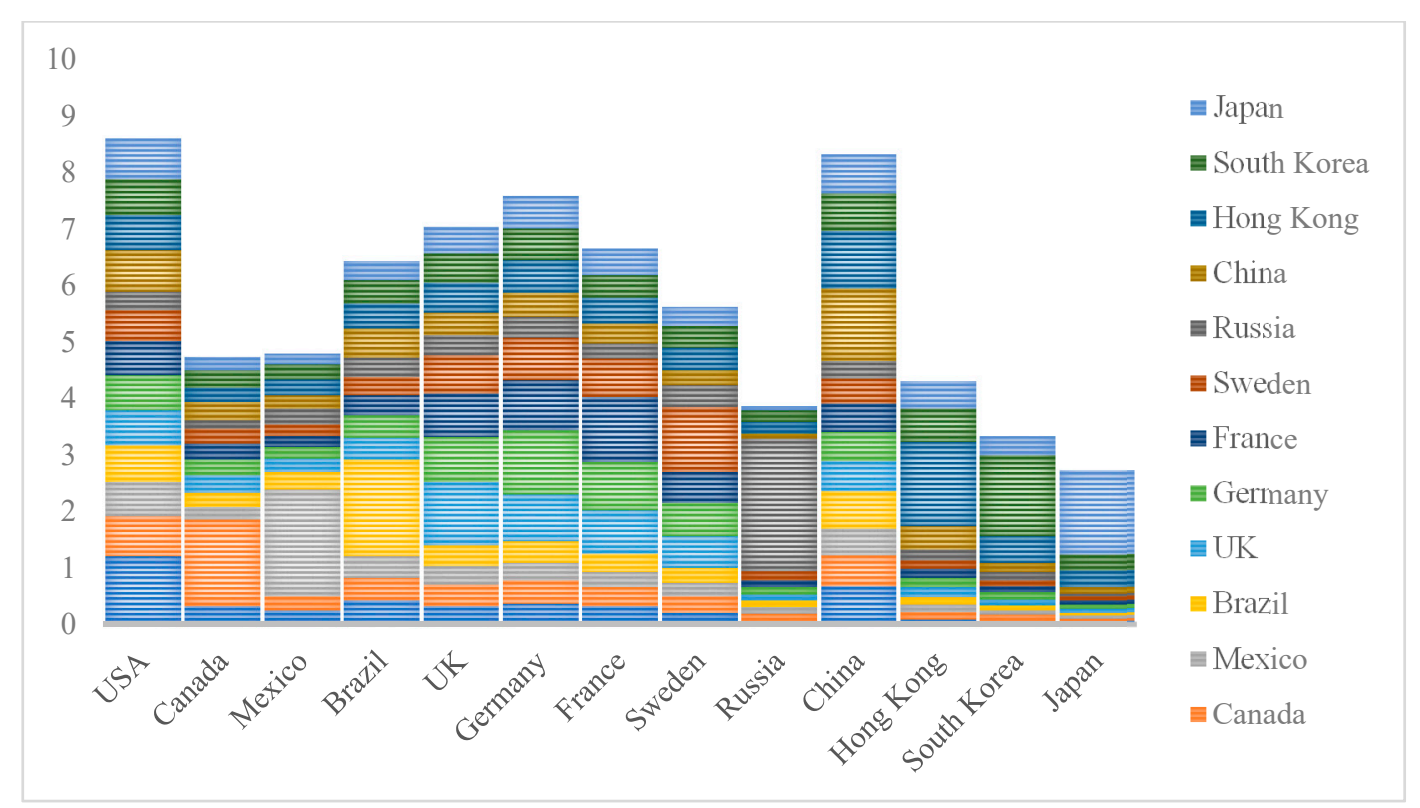

Figure 3. Long-term connectedness.

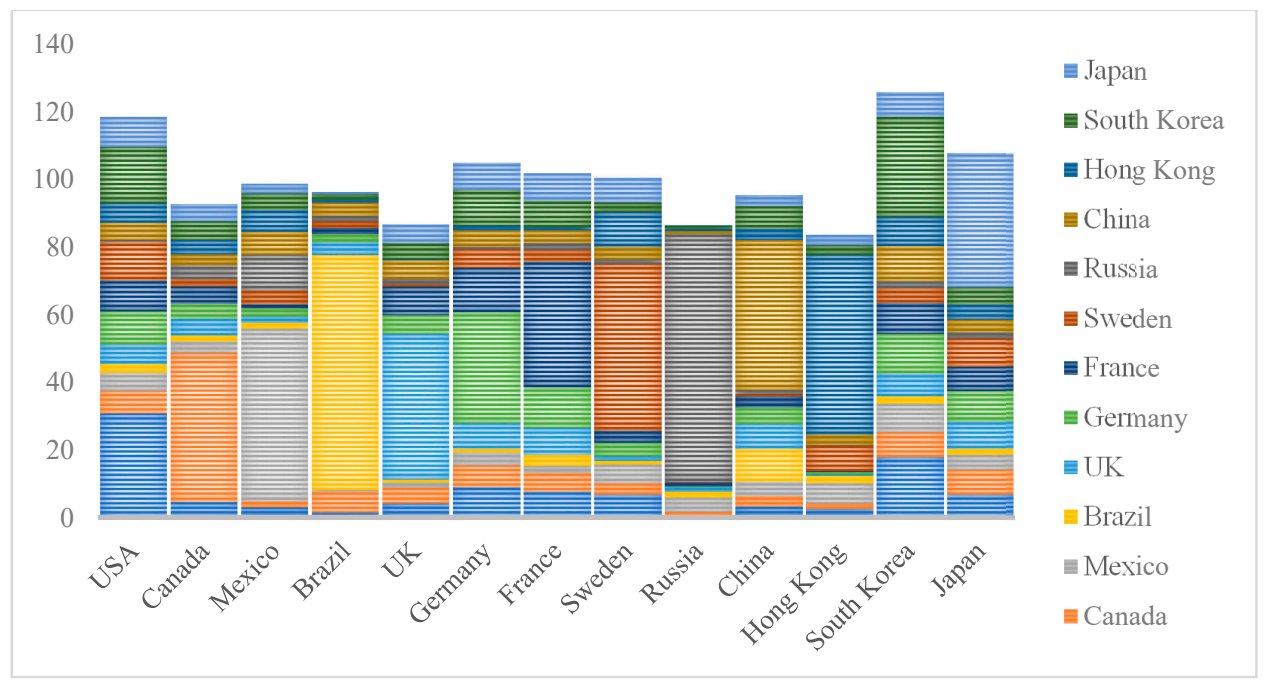

Figure 4. Economic policy uncertainty (EPU) connectedness.

Another important feature of the fear connectedness is that of regional heterogeneity. Figures 1-3 shows that much of the contribution to European stock market spillovers, namely UK, Germany, France, and Sweden, comes from the European counterparts, not from those in other regions. These findings are in line with [7], who conclude that in contrast to the markets in Americas and Asia, the stock market fear is strongly connected among European countries. On the other hand, much of the spillovers are caused by their own share of fear shocks for the American and Asian markets. The higher level of fear connectedness among European stock markets points to the higher levels of economic and financial integration in the post European and Monetary Union (EMU) period across these countries, resulting in more synchronized responses from market participants in these markets.

Further, panel A (Figure 1) of Table A2 indicates that the US (2.89\%), Germany (2.51\%), and China $(2.29 \%)$ are the highest net-transmitters of fear shocks, while Japan $(-3.63 \%)$, South Korea $(-3.02 \%)$, 
and Hong Kong $(-2.23 \%)$ are the most popular net-recipients of those shocks. Across panels B (Figure 2) and C (Figure 3), the US, Germany, China continue to be the primary transmitters of fear over the short-and long-term horizons, while Japan, South Korea, and Hong Kong remain as the leading recipients of fear shock across the frequency bands. Being among dominant stock markets in the world and European stock markets, the US and Germany's fear shocks are more contagious towards other markets, a finding also supported by $[7,19,21]$. However, China is quite remarkable as one of the top transmitters of shocks of fear. Their growing influence on the world stock markets coupled with the 2015 crash of the Chinese market could be the underlying cause of this outcome, where the Chinese market adversely affected many stock markets around the world, particularly the major Asian markets such as Japan, South Korea, and Hong Kong. These results find support by recent studies, such as [35].

Next, we explore the extent to which EPU connectedness drives the cross-country connectedness of fear. To that end, the pairwise EPU connectedness estimates, shown in panel D (Figure 4), are used in the cross-sectional regression given in Equations (1)-(3), where the pairwise fear connectedness estimates, shown in panel A-C (Figures 1-3), are used as the dependent variable. In all regressions, the pairwise EPU connectedness remains our variable of interest. In Table 1, panels A, B, and C present the regression results for the pairwise (total, short-, and long-term) fear connectedness, respectively. In each panel, column (1) includes the results of our base regression described in Equation (7), which is the univariate model. Column (2) presents the results of the regression model, Equation (8), where we control for bilateral linkages, whereas the model results shown in column (3) include additional control variables for country-specific factors, see Equation (9).

The univariate model in panel A1 (Table 1) shows that the transmission of fear shocks from country $i$ to country $j$ is significantly driven by the transmission of EPU from country $i$ to country $j$. A percentage increase in EPU connectedness between the two countries leads to a 0.248 percent rise in the fear connectedness of their stock markets. In panel A2, EPU connectedness continues to show reasonable explanatory potential even after controlling for bilateral linkages. In panel A3, even after controlling for two country-specific factors, the EPU connectedness continues to drive the fear connectedness with a reasonable magnitude (0.144). This finding that EPU connectedness drives the fear connectedness between a pair of countries extends the current understanding of how EPU may amplify the transmission of stock market volatility, such as that of [19], who argues that the EPU of major economies leads the systemic risk of regions.

Expectedly-since the overall and pairwise estimates for the total and short-term fear connectedness are roughly similar-the findings in panel B mirror those in panel A, as we notice that the EPU connectedness strongly drives the short-term connectedness of fear across global stock markets. These findings confirm the inference of [11] for G7 countries that EPU spillover is a short-term predictor of financial stress spillovers. Our finding that EPU connectedness strongly drives the short-term connectedness of fear might be an indicator of how international market participants have become increasingly concerned about the spread of EPU shocks across countries. It is well known that the global economies have adopted expansionary economic policies to combat the threat of another economic recession, which resulted from the GFC (the International Monetary Fund has repeatedly warned in its reports that the hot money derived from such policies may lead to another financial crisis). Such coherent policy initiatives have interfered with the global economy, leading to increased worries among market participants about EPU shocks (and financial markets). Consequently, the EPU shocks are rapidly transmitting across countries and triggering transnational spillovers of fear. Tsai [26] documents several examples of policy related events that drive short-term responses from stock markets around the world. A typical example was when in June 2015 a black swan event affected many stock markets around the world, and the stock indices of China, Japan, the United States, and European countries collapsed by huge amounts. The primary reason behind these large price declines was the plans by the US Fed to raise interest rates, which lead to panic among investors, and hence to the fear spillovers around the world. 
Table 1. Determinants of net-pairwise fear shock transmission.

\begin{tabular}{|c|c|c|c|c|c|c|c|c|c|}
\hline Variable & 1 & 2 & 3 & 1 & 2 & 3 & 1 & 2 & 3 \\
\hline & \multicolumn{3}{|c|}{ Panel A: Total } & \multicolumn{3}{|c|}{ Panel B: Short-Term } & \multicolumn{3}{|c|}{ Panel C: Long-Term } \\
\hline EPU ij & $\begin{array}{c}0.248^{* * * *} \\
(0.085)\end{array}$ & $\begin{array}{c}0.163^{* *} \\
(0.075)\end{array}$ & $\begin{array}{l}0.144^{*} \\
(0.077)\end{array}$ & $\begin{array}{c}0.234^{* * *} \\
(0.080)\end{array}$ & $\begin{array}{c}0.152 * * \\
(0.071)\end{array}$ & $\begin{array}{l}0.134^{*} \\
(0.073)\end{array}$ & $\begin{array}{c}0.014^{* * *} \\
(0.005)\end{array}$ & $\begin{array}{c}0.010^{* *} \\
(0.005)\end{array}$ & $\begin{array}{c}0.010 * * \\
(0.005)\end{array}$ \\
\hline Cont ij & & $\begin{array}{l}-0.138 \\
(1.201) \\
\end{array}$ & $\begin{array}{l}-0.198 \\
(1.223) \\
\end{array}$ & & $\begin{array}{l}-0.159 \\
(1.132)\end{array}$ & $\begin{array}{l}-0.210 \\
(1.154)\end{array}$ & & $\begin{array}{c}0.021 \\
(0.073) \\
\end{array}$ & $\begin{array}{c}0.012 \\
(0.073) \\
\end{array}$ \\
\hline Col ij & & $\begin{array}{l}-0.529 \\
(1.148)\end{array}$ & $\begin{array}{l}-0.560 \\
(1.178)\end{array}$ & & $\begin{array}{l}-0.494 \\
(1.082)\end{array}$ & $\begin{array}{l}-0.537 \\
(1.112)\end{array}$ & & $\begin{array}{l}-0.036 \\
(0.070)\end{array}$ & $\begin{array}{l}-0.023 \\
(0.070)\end{array}$ \\
\hline$\underset{\text { ij }}{\text { Comm_Lang }}$ & & $\begin{array}{c}0.180 \\
(1.042) \\
\end{array}$ & $\begin{array}{c}0.194 \\
(1.148) \\
\end{array}$ & & $\begin{array}{l}0.129 \\
(0.983) \\
\end{array}$ & $\begin{array}{c}0.151 \\
(1.084)\end{array}$ & & $\begin{array}{c}0.052 \\
(0.064)\end{array}$ & $\begin{array}{c}0.043 \\
(0.069) \\
\end{array}$ \\
\hline Dist ij & & $\begin{array}{c}-1.723^{* * *} \\
(0.301)\end{array}$ & $\begin{array}{c}-1.706^{* * *} \\
(0.310)\end{array}$ & & $\begin{array}{c}-1.633^{* * *} \\
(0.284)\end{array}$ & $\begin{array}{c}-1.614^{* * *} \\
(0.293)\end{array}$ & & $\begin{array}{c}-0.090 * * * \\
(0.018)\end{array}$ & $\begin{array}{c}-0.092 * * * \\
(0.019)\end{array}$ \\
\hline Trade ij & & $\begin{array}{c}0.336^{* * *} \\
(0.124)\end{array}$ & $\begin{array}{c}0.368^{* * *} \\
(0.130)\end{array}$ & & $\begin{array}{c}0.327 * * * \\
(0.117)\end{array}$ & $\begin{array}{c}0.355^{* * *} \\
(0.123)\end{array}$ & & $\begin{array}{c}0.009 \\
(0.008) \\
\end{array}$ & $\begin{array}{c}0.012 \\
(0.008) \\
\end{array}$ \\
\hline Trade_Open i & & & $\begin{array}{l}-0.006 \\
(0.004)\end{array}$ & & & $\begin{array}{l}-0.005 \\
(0.003)\end{array}$ & & & $\begin{array}{l}0.001 * \\
(0.000)\end{array}$ \\
\hline Trade_Open j & & & $\begin{array}{c}0.005 \\
(0.004)\end{array}$ & & & $\begin{array}{c}0.004 \\
(0.003)\end{array}$ & & & $\begin{array}{l}0.001 \text { ** } \\
(0.000)\end{array}$ \\
\hline Fin_Open i & & & $\begin{array}{c}0.194 \\
(0.212) \\
\end{array}$ & & & $\begin{array}{c}0.195 \\
(0.200)\end{array}$ & & & $\begin{array}{l}-0.001 \\
(0.013)\end{array}$ \\
\hline Fin_Open j & & & $\begin{array}{l}-0.176 \\
(0.213)\end{array}$ & & & $\begin{array}{l}-0.165 \\
(0.201)\end{array}$ & & & $\begin{array}{l}-0.011 \\
(0.013)\end{array}$ \\
\hline R-Squared & 0.052 & 0.334 & 0.351 & 0.052 & 0.339 & 0.353 & 0.048 & 0.250 & 0.308 \\
\hline
\end{tabular}

Note: The table reports the results of cross-sectional estimations. HAC standard errors are in parentheses. ${ }^{*}, * * * * *$ indicates significance at $10 \%, 5 \%$, and $1 \%$, respectively. EPU $\mathrm{ij}_{\mathrm{ij}}$ is EPU spillover from country $i$ to country $j$. Cont $t_{i j}, C_{i j}$, and Comm_Lang ${ }_{i j}$, are the dummy variables representing border sharing, colonial ties, and common language of two countries, respectively. Dist ${ }_{i j}$ and Trade $\mathrm{ij}_{\mathrm{ij}}$, respectively, represent the geographical distance (in kilometres) and bilateral trade between two countries. Trade_Open ${ }_{\mathrm{i}}\left(\mathrm{Fin}_{\mathrm{Openi}}\right)$ and Trade_Open $_{\mathrm{j}}$ $\left(\right.$ Fin_Open ${ }_{j}$ ) represent trade openness (financial openness) of country $i$ and country $j$, respectively. 
In panel C, however, although EPU connectedness drives long-term connectedness of fear, the coefficients are now much smaller. Higher EPU combined with higher financial uncertainty might render market participants' sentiments to persist in the long-term, in turn, driving the long-term connectedness of fear [2]. Finally, note that, apart from EPU connectedness as the primary driver of fear connectedness, bilateral linkages, namely bilateral trade and common distance, and country-specific factors, i.e., trade openness of the partner country, also play an important role in transmitting the fear shock across borders. Trade openness, nonetheless, only matters for the log-term transmission of fear.

\section{Conclusions}

Given scant literature exploring the driving potential of EPU for stock market spillovers, we consider a multi-country context to investigate this potential. Specifically, we examine the extent to which EPU connectedness drives the fear connectedness across world stock markets. Overall, we find that the short-term transmission of fear is substantially higher than that over long-term horizons. More importantly, EPU connectedness between any two partner countries is a strong driver of fear connectedness between their stock markets. The driving impact of EPU connectedness holds not only after accounting for bilateral linkages and country-specific factors but also for short-and long-term connectedness of fear.

By performing a pair-wise analysis of a wide range of economies, this study delves deeper and goes beyond the network-based interactions between EPU and regional spillovers of stock market volatility, such as [11,26]. Our findings are, therefore, not only insightful to investors of specific regions but also to investors around the world by uncovering the possible driving effects of EPU spillovers on fear spillovers. In particular, this study cautions investors about the fear shocks coming from foreign markets, and how the interaction between local and foreign EPUs can intensify the transmission of those shocks. This becomes even more critical for international investors who typically invest in multiple countries and, as such, are exposed to shocks from multiple countries. Our results imply that while the driving potential of EPU interconnection for transmitting fear shocks matters more in the short-term, close attention should be given to the long-term driving effects, in that financial and macro uncertainties could combine to possibly cause the transmission of fear shocks over the longer horizons. Global financial bodies like the World Bank and the International Monetary Fund might strengthen their policy risk assessments in the pair-wise context. Because ensuring financial stability is the vital component of promoting economic growth in a global environment.

One obvious limitation of this study relates to the availability of data. While EPU indices are available for more than twenty countries, fear indices are only available for those included in our sample. The study can be expanded further to include more countries once the fear and EPU indices are constructed and made available for a wider sample of countries. This would be beneficial for drawing comparisons between emerging and developed economies, as transmission EPU is much higher across the former group than the later.

Author Contributions: Conceptualization, M.H.; methodology, M.H., and M.A.N.; software, M.H., and M.A.N.; validation, M.H., M.A.N., and M.A.; formal analysis, M.H., and M.A.N.; investigation, M.H., M.A.N.; resources, S.M.N. and S.J.H.S.; data curation, M.H., M.A.N., and M.A.; writing-original draft preparation, M.H.; writing-review and editing, S.M.N., M.A, and S.J.H.S.; visualization, M.A.N., and S.J.H.S..; supervision, S.J.H.S.; funding acquisition, S.M.N. All authors have read and agreed to the published version of the manuscript.

Funding: The APC was funded by RHB Islamic Endowed Scholar in Finance research grant (vote: 53276). The authors are grateful to RHB Islamic Bank Berhad for the financial support.

Conflicts of Interest: The authors declare no conflict of interest. The funders had no role in the design of the study; in the collection, analyses, or interpretation of data; in the writing of the manuscript, or in the decision to publish the results.

\section{Appendix A}

Table A2 shows the fear connectedness across our sample countries. Panel A includes the total connectedness of fear computed from Diebold and Yilmaz [16] model. Panels B and C contain the 
short- and long-term connectedness obtained from the model proposed by Baruník and Křehlík [17]. In our case, the frequency bands of BK correspond to movements over 1-22 days (one month) and 23-250 days (one year), representing short- and long-term dynamics of fear connectedness, respectively. In each panel, rows (columns) include the fear shocks each country receives from and sends to another country; To (From) represent the row (column) that includes the total spillovers each country sends to (receives from) all other countries. NET indicates whether a country is a transmitter (positive) or receiver (negative) of fear shocks, while Total shows the overall connectedness exhibited by the whole system.

Table A3 shows the EPU connectedness across our sample countries computed from Diebold and Yilmaz [16] model. Rows (columns) include the EPU shocks each country receives from and sends to another country; To (From) represent the row (column) that includes the total EPU spillovers each country sends to (receives from) all other countries. NET indicates whether a country is a transmitter (positive) or receiver (negative) of EPU shocks, while Total shows the overall connectedness exhibited by the whole system. 
Table A1. List of the countries and variables.

\begin{tabular}{|c|c|c|}
\hline \multirow{2}{*}{$\begin{array}{c}\text { Countries (Notation) } \\
\text { Variables }\end{array}$} & \multicolumn{2}{|c|}{$\begin{array}{l}\text { Brazil (BRA), Canada (CAN), China (CHN), France (FRA), Germany (GER), Hong Kong (HKG), Japan (JPN), Mexico (MEX), } \\
\text { Russia (RUS), South Korea (SKR), Sweden (SWE), United Kingdom (UK), United States (USA) }\end{array}$} \\
\hline & Measurement & Source \\
\hline $\mathrm{EPU}_{\mathrm{ij}}$ & EPU spillover from country $i$ to country $j$. & Author's calculation via Diebold and Yilmaz [16] \\
\hline Cont $_{\mathrm{ij}}$ & $\begin{array}{c}\text { A binary variable tt takes } 1 \text { if the origin country } i \text { and country } j \text { share a } \\
\text { border, } 0 \text { otherwise. }\end{array}$ & $\begin{array}{l}\text { French Research Center in International } \\
\text { Economics-(CEPII) }\end{array}$ \\
\hline $\operatorname{Col}_{i j}$ & $\begin{array}{c}\text { A binary variable that takes } 1 \text { if the origin country } i \text { and cntry } j \text { have had } \\
\text { colonial ties, and } 0 \text { otherwise. }\end{array}$ & CEPII \\
\hline Comm_Lang & $\begin{array}{l}\text { A binary variable that takes } 1 \text { if the origin country } i \text { and country } j \text { share at } \\
\text { least one common language, and 0therwise. }\end{array}$ & CEPII \\
\hline Dist $_{\mathrm{ij}}$ & $\begin{array}{l}\text { Is the physical distance (in kilometers) between the origin country } i \text { and } \\
\text { country } j .\end{array}$ & PII \\
\hline Trade $_{i j}$ & $\begin{array}{l}\text { Is the trade volume between origin country } i \text { and country } j \text {. It is the } \\
\text { average for the period between } 2011-2018 \text {. }\end{array}$ & F's database \\
\hline $\begin{array}{l}\text { Fin_Openi } \\
\text { Fin_Open }\end{array}$ & $\begin{array}{l}\text { Is the financial openness index of the country, constructed by Chinn and } \\
\text { Ito [27]. It is the average for the period between 2011-2018. }\end{array}$ & http://web.pdx.edu/ ito/Chinn-Ito_website.htm \\
\hline Trade_Open $_{\mathrm{i}}$,Trade_Open & $\begin{array}{l}\text { Is exports plus imports relative to the GDP of the country. It is the average } \\
\text { for the period between 2011-2018. }\end{array}$ & World Development Indicators (WDI), World Bank \\
\hline
\end{tabular}


Table A2. Directional shock transmission of Fear indexes.

\begin{tabular}{|c|c|c|c|c|c|c|c|c|c|c|c|c|c|c|}
\hline \multicolumn{15}{|c|}{ Panel A: Total } \\
\hline & USA & CAN & MEX & BRA & UK & GER & FRA & SWE & RUS & CHN & HKG & SKR & JPN & FROM \\
\hline USA & 28.519 & 7.223 & 5.637 & 9.225 & 7.430 & 8.394 & 7.870 & 5.616 & 1.386 & 14.700 & 1.549 & 1.111 & 1.340 & 5.499 \\
\hline CAN & 10.734 & 41.754 & 3.330 & 5.572 & 6.069 & 6.913 & 5.777 & 4.796 & 1.917 & 8.855 & 1.869 & 1.800 & 0.612 & 4.480 \\
\hline MEX & 9.435 & 3.607 & 47.729 & 6.582 & 5.388 & 5.261 & 4.347 & 4.347 & 2.049 & 7.547 & 1.797 & 1.044 & 0.867 & 4.021 \\
\hline BRA & 11.490 & 4.538 & 4.969 & 35.308 & 6.708 & 7.199 & 6.374 & 5.239 & 1.857 & 12.327 & 1.950 & 1.255 & 0.786 & 4.976 \\
\hline UK & 7.893 & 4.209 & 3.123 & 5.142 & 23.760 & 15.557 & 14.205 & 10.876 & 1.718 & 7.581 & 2.860 & 1.842 & 1.232 & 5.865 \\
\hline GER & 8.104 & 4.143 & 2.837 & 5.246 & 14.649 & 22.305 & 15.409 & 11.414 & 2.032 & 7.431 & 2.984 & 2.108 & 1.338 & 5.977 \\
\hline FRA & 8.038 & 3.828 & 2.544 & 4.898 & 14.689 & 16.862 & 24.649 & 10.588 & 1.666 & 7.143 & 2.549 & 1.405 & 1.143 & 5.796 \\
\hline SWE & 6.894 & 3.703 & 2.838 & 4.485 & 12.745 & 14.241 & 12.063 & 28.166 & 2.806 & 6.323 & 2.701 & 1.891 & 1.145 & 5.526 \\
\hline RUS & 3.920 & 2.214 & 3.432 & 4.091 & 4.585 & 5.311 & 3.834 & 5.883 & 56.647 & 3.722 & 3.313 & 2.476 & 0.572 & 3.335 \\
\hline CHN & 13.487 & 5.623 & 4.149 & 9.080 & 7.691 & 8.080 & 7.077 & 5.576 & 1.306 & 25.964 & 7.115 & 2.696 & 2.156 & 5.695 \\
\hline HKG & 9.156 & 2.943 & 3.576 & 5.782 & 6.555 & 7.018 & 5.710 & 5.133 & 2.483 & 11.997 & 27.641 & 7.268 & 4.738 & 5.566 \\
\hline SKR & 9.414 & 3.470 & 3.638 & 5.321 & 6.452 & 7.221 & 5.108 & 5.069 & 2.602 & 7.713 & 8.496 & 31.235 & 4.261 & 5.290 \\
\hline JPN & 10.444 & 3.318 & 2.390 & 4.432 & 6.615 & 8.235 & 7.053 & 4.921 & 0.791 & 8.426 & 6.160 & 4.623 & 32.591 & 5.185 \\
\hline TO & 8.385 & 3.755 & 3.266 & 5.374 & 7.660 & 8.484 & 7.294 & 6.112 & 1.740 & 7.982 & 3.334 & 2.271 & 1.553 & TOTAL \\
\hline NET & 2.887 & -0.725 & -0.754 & 0.397 & 1.795 & 2.507 & 1.498 & 0.586 & -1.595 & 2.287 & -2.232 & -3.019 & -3.632 & $67.210 \%$ \\
\hline \multicolumn{15}{|c|}{ Panel B: Short-Term } \\
\hline & USA & CAN & MEX & BRA & UK & GER & FRA & SWE & RUS & CHN & HKG & SKR & JPN & FROM \\
\hline USA & 27.308 & 6.888 & 5.381 & 8.799 & 7.099 & 8.028 & 7.542 & 5.399 & 1.322 & 14.023 & 1.454 & 1.049 & 1.278 & 5.251 \\
\hline CAN & 10.018 & 40.230 & 3.088 & 5.171 & 5.692 & 6.492 & 5.436 & 4.513 & 1.778 & 8.304 & 1.743 & 1.682 & 0.570 & 4.191 \\
\hline MEX & 8.835 & 3.383 & 45.828 & 6.189 & 5.060 & 4.948 & 4.088 & 4.104 & 1.931 & 7.074 & 1.666 & 0.971 & 0.807 & 3.774 \\
\hline BRA & 10.838 & 4.285 & 4.665 & 33.605 & 6.340 & 6.826 & 6.038 & 4.976 & 1.749 & 11.668 & 1.811 & 1.171 & 0.741 & 4.701 \\
\hline UK & 7.281 & 3.905 & 2.889 & 4.756 & 22.638 & 14.729 & 13.438 & 10.309 & 1.605 & 7.044 & 2.684 & 1.729 & 1.153 & 5.502 \\
\hline GER & 7.487 & 3.852 & 2.625 & 4.853 & 13.854 & 21.161 & 14.560 & 10.826 & 1.901 & 6.916 & 2.817 & 1.981 & 1.261 & 5.610 \\
\hline FRA & 7.427 & 3.557 & 2.351 & 4.537 & 13.917 & 15.986 & 23.496 & 10.047 & 1.550 & 6.642 & 2.394 & 1.305 & 1.071 & 5.445 \\
\hline SWE & 6.353 & 3.437 & 2.629 & 4.156 & 12.060 & 13.481 & 11.391 & 27.009 & 2.644 & 5.875 & 2.544 & 1.775 & 1.073 & 5.186 \\
\hline RUS & 3.587 & 2.058 & 3.160 & 3.754 & 4.244 & 4.941 & 3.561 & 5.509 & 54.301 & 3.411 & 3.120 & 2.332 & 0.525 & 3.092 \\
\hline CHN & 12.755 & 5.305 & 3.904 & 8.561 & 7.278 & 7.646 & 6.718 & 5.301 & 1.223 & 24.680 & 6.699 & 2.531 & 2.040 & 5.382 \\
\hline HKG & 8.537 & 2.682 & 3.300 & 5.340 & 6.024 & 6.451 & 5.252 & 4.739 & 2.280 & 10.981 & 26.163 & 6.804 & 4.442 & 5.141 \\
\hline SKR & 8.780 & 3.172 & 3.374 & 4.912 & 5.945 & 6.651 & 4.714 & 4.685 & 2.390 & 7.046 & 7.893 & 29.800 & 3.986 & 4.888 \\
\hline JPN & 9.720 & 3.081 & 2.194 & 4.098 & 6.140 & 7.663 & 6.578 & 4.584 & 0.721 & 7.740 & 5.682 & 4.287 & 31.103 & 4.807 \\
\hline TO & 7.817 & 3.508 & 3.043 & 5.010 & 7.204 & 7.988 & 6.870 & 5.769 & 1.623 & 7.440 & 3.116 & 2.124 & 1.457 & TOTAL \\
\hline NET & 2.566 & -0.683 & -0.731 & 0.309 & 1.703 & 2.378 & 1.426 & 0.582 & -1.470 & 2.059 & -2.025 & -2.764 & -3.349 & $62.970 \%$ \\
\hline
\end{tabular}


Table A2. Cont.

\begin{tabular}{|c|c|c|c|c|c|c|c|c|c|c|c|c|c|c|}
\hline \multicolumn{15}{|c|}{ Panel C: Long-Term } \\
\hline & USA & CAN & MEX & BRA & UK & GER & FRA & SWE & RUS & CHN & HKG & $\begin{array}{l}\text { SKR } \\
\end{array}$ & JPN & FROM \\
\hline USA & 1.212 & 0.335 & 0.257 & 0.426 & 0.330 & 0.366 & 0.328 & 0.216 & 0.063 & 0.677 & 0.095 & 0.061 & 0.062 & 0.248 \\
\hline CAN & 0.716 & 1.525 & 0.242 & 0.401 & 0.377 & 0.422 & 0.342 & 0.283 & 0.139 & 0.551 & 0.126 & 0.119 & 0.042 & 0.289 \\
\hline MEX & 0.600 & 0.224 & 1.901 & 0.393 & 0.328 & 0.313 & 0.259 & 0.244 & 0.118 & 0.473 & 0.131 & 0.072 & 0.060 & 0.247 \\
\hline BRA & 0.652 & 0.253 & 0.304 & 1.703 & 0.368 & 0.372 & 0.336 & 0.263 & 0.108 & 0.659 & 0.138 & 0.084 & 0.045 & 0.276 \\
\hline UK & 0.613 & 0.304 & 0.234 & 0.386 & 1.122 & 0.828 & 0.767 & 0.567 & 0.113 & 0.537 & 0.176 & 0.113 & 0.079 & 0.363 \\
\hline GER & 0.617 & 0.290 & 0.212 & 0.394 & 0.795 & 1.145 & 0.849 & 0.588 & 0.132 & 0.515 & 0.166 & 0.126 & 0.076 & 0.366 \\
\hline FRA & 0.611 & 0.271 & 0.192 & 0.361 & 0.772 & 0.875 & 1.153 & 0.542 & 0.115 & 0.501 & 0.154 & 0.100 & 0.072 & 0.351 \\
\hline SWE & 0.540 & 0.266 & 0.208 & 0.328 & 0.685 & 0.760 & 0.672 & 1.157 & 0.162 & 0.447 & 0.157 & 0.116 & 0.072 & 0.340 \\
\hline RUS & 0.334 & 0.156 & 0.272 & 0.336 & 0.341 & 0.370 & 0.273 & 0.373 & 2.346 & 0.311 & 0.193 & 0.145 & 0.047 & 0.242 \\
\hline CHN & 0.732 & 0.317 & 0.245 & 0.519 & 0.412 & 0.434 & 0.359 & 0.275 & 0.083 & 1.285 & 0.416 & 0.165 & 0.116 & 0.313 \\
\hline HKG & 0.618 & 0.261 & 0.276 & 0.441 & 0.531 & 0.567 & 0.457 & 0.394 & 0.203 & 1.016 & 1.478 & 0.463 & 0.297 & 0.425 \\
\hline SKR & 0.634 & 0.299 & 0.264 & 0.408 & 0.507 & 0.569 & 0.394 & 0.384 & 0.212 & 0.667 & 0.603 & 1.435 & 0.275 & 0.401 \\
\hline JPN & 0.724 & 0.237 & 0.196 & 0.334 & 0.474 & 0.572 & 0.475 & 0.338 & 0.070 & 0.687 & 0.478 & 0.336 & 1.488 & 0.379 \\
\hline TO & 0.569 & 0.247 & 0.223 & 0.364 & 0.455 & 0.496 & 0.424 & 0.344 & 0.117 & 0.542 & 0.218 & 0.146 & 0.096 & TOTAL \\
\hline NET & 0.321 & -0.042 & -0.024 & 0.088 & 0.093 & 0.130 & 0.073 & 0.004 & -0.126 & 0.228 & -0.207 & -0.255 & -0.283 & $4.240 \%$ \\
\hline
\end{tabular}

Note: This table presents the estimated results based on VAR (2). Panel A presents the results for total connectedness using Diebold and Yilmaz [16], whereas Panels B and C present the results for short- and long-term frequency connectedness using Baruník and Křehlík [17].

Table A3. Directional shock transmission of EPU indexes.

\begin{tabular}{|c|c|c|c|c|c|c|c|c|c|c|c|c|c|c|}
\hline & USA & CAN & MEX & BRA & UK & GER & FRA & SWE & RUS & CHN & HKG & SKR & JPN & FROM \\
\hline USA & 31.011 & 4.786 & 3.170 & 1.554 & 4.211 & 9.232 & 7.925 & 6.889 & 0.244 & 3.394 & 2.693 & 17.956 & 6.934 & 5.307 \\
\hline CAN & 6.564 & 44.159 & 1.744 & 6.225 & 4.729 & 6.438 & 5.571 & 3.376 & 1.678 & 3.147 & 1.675 & 7.425 & 7.269 & 4.295 \\
\hline MEX & 5.367 & 3.355 & 50.962 & 0.426 & 1.637 & 3.625 & 1.814 & 5.639 & 4.170 & 4.197 & 5.875 & 8.336 & 4.597 & 3.772 \\
\hline BRA & 2.718 & 1.684 & 1.775 & 69.413 & 0.804 & 1.128 & 3.368 & 1.118 & 1.809 & 9.794 & 2.308 & 2.392 & 1.687 & 2.353 \\
\hline UK & 5.699 & 4.822 & 1.986 & 3.888 & 42.991 & 7.634 & 8.080 & 1.359 & 1.382 & 7.310 & 0.350 & 6.584 & 7.914 & 4.385 \\
\hline GER & 9.776 & 4.520 & 2.410 & 2.467 & 5.652 & 32.860 & 11.952 & 3.824 & 0.125 & 4.849 & 0.697 & 11.750 & 9.119 & 5.165 \\
\hline FRA & 9.055 & 5.033 & 1.128 & 1.659 & 8.345 & 13.020 & 37.083 & 3.525 & 1.079 & 3.398 & 0.287 & 9.143 & 7.245 & 4.840 \\
\hline SWE & 11.510 & 2.264 & 4.013 & 2.056 & 0.731 & 5.460 & 3.525 & 49.292 & 0.286 & 0.649 & 7.438 & 4.351 & 8.424 & 3.901 \\
\hline RUS & 0.523 & 3.911 & 10.480 & 1.476 & 1.466 & 0.795 & 1.892 & 1.407 & 73.116 & 1.035 & 0.246 & 2.015 & 1.639 & 2.068 \\
\hline CHN & 5.060 & 3.335 & 6.848 & 4.023 & 5.695 & 4.789 & 3.902 & 3.619 & 0.996 & 44.445 & 3.068 & 10.473 & 3.745 & 4.273 \\
\hline HKG & 5.733 & 4.259 & 6.505 & 0.998 & 0.227 & 1.295 & 0.770 & 10.306 & 0.550 & 3.282 & 52.970 & 8.672 & 4.432 & 3.618 \\
\hline SKR & 16.715 & 5.482 & 4.834 & 1.518 & 4.707 & 10.736 & 7.871 & 2.775 & 1.003 & 6.620 & 3.065 & 29.409 & 5.265 & 5.430 \\
\hline JPN & 8.788 & 5.104 & 2.938 & 0.573 & 5.671 & 8.058 & 8.049 & 7.484 & 0.062 & 3.417 & 2.918 & 7.330 & 39.608 & 4.646 \\
\hline TO & 6.731 & 3.735 & 3.679 & 2.066 & 3.375 & 5.555 & 4.979 & 3.948 & 1.029 & 3.930 & 2.355 & 7.417 & 5.252 & TOTAL \\
\hline NET & 1.425 & -0.560 & -0.093 & -0.286 & -1.010 & 0.390 & 0.139 & 0.047 & -1.039 & -0.343 & -1.262 & 1.987 & 0.606 & $54.052 \%$ \\
\hline
\end{tabular}

Note: This table presents the estimated results based on VAR (2) using Diebold and Yilmaz [16]. 


\section{References}

1. Ngene, G.; Post, J.A.; Mungai, A.N. Volatility and shock interactions and risk management implications: Evidence from the US and frontier markets. Emerg. Mark. Rev. 2018, 37, 181-198. [CrossRef]

2. Wang, C. Fear factor: Does the VIXC provide the most accurate forecast of Canadian stock market volatility? Can. Inv. Rev. 2011, 2011, 10-16.

3. Bouri, E.; Gupta, R.; Hosseini, S.; Lau, C.K.M. Does global fear predict fear in BRICS stock markets? Evidence from a Bayesian Graphical Structural VAR model. Emerg. Mark. Rev. 2018, 34, 124-142. [CrossRef]

4. Ji, Q.; Bouri, E.; Roubaud, D. Dynamic network of implied volatility transmission among US equities, strategic commodities, and BRICS equities. Int. Rev. Financ. Anal. 2018, 57, 1-12. [CrossRef]

5. Pastor, L.; Veronesi, P. Uncertainty about government policy and stock prices. J. Financ. 2012, 67, $1219-1264$. [CrossRef]

6. Badshah, I.U. Volatility spillover from the fear index to developed and emerging markets. Emerg. Mark. Financ. Trade 2018, 54, 27-40. [CrossRef]

7. BenSaïda, A.; Litimi, H.; Abdallah, O. Volatility spillover shifts in global financial markets. Econ. Model. 2018, 73, 343-353. [CrossRef]

8. Balli, F.; Uddin, G.S.; Mudassar, H.; Yoon, S.M. Cross-country determinants of economic policy uncertainty spillovers. Econ. Lett. 2017, 156, 179-183. [CrossRef]

9. Yin, L.; Han, L. Spillovers of macroeconomic uncertainty among major economies. Appl. Econ. Lett. 2014, 21, 938-944. [CrossRef]

10. Kang, S.H.; Yoon, S.M. Dynamic connectedness network in economic policy uncertainties. Appl. Econ. Lett. 2019, 26, 74-78. [CrossRef]

11. Liow, K.H.; Liao, W.C.; Huang, Y. Dynamics of international spillovers and interaction: Evidence from financial market stress and economic policy uncertainty. Econ. Model. 2018, 68, 96-116. [CrossRef]

12. Carr, P.; Madan, D. Towards a theory of volatility trading. In Volatility Estimation Techniques for Pricing Derivatives; Jarrow, R., Ed.; Risk Books: London, UK, 1998; pp. 417-427.

13. Demeterfi, K.; Derman, E.; Kamal, M.; Zou, J. A guide to volatility and variance swaps. J. Deriv. 1999, 6, 9-32. [CrossRef]

14. Belke, A.; Dubova, I.; Osowski, T. Policy uncertainty and international financial markets: The case of Brexit. Appl. Econ. 2018, 50, 3752-3770. [CrossRef]

15. Ehrmann, M.; Fratzscher, M. Global financial transmission of monetary policy shocks. Oxf. Bull. Econ. Stat. 2009, 71, 739-759. [CrossRef]

16. Diebold, F.X.; Yilmaz, K. Better to give than to receive: Predictive directional measurement of volatility spillovers. Int. J. Forecast. 2012, 28, 57-66. [CrossRef]

17. Baruník, J.; Křehlík, T. Measuring the frequency dynamics of financial connectedness and systemic risk. J. Financ. Econom. 2018, 16, 271-296. [CrossRef]

18. Äijö, J. Implied volatility term structure linkages between VDAX, VSMI and VSTOXX volatility indices. Glob. Financ. J. 2008, 18, 290-302. [CrossRef]

19. Tsai, I.C. Spillover of fear: Evidence from the stock markets of five developed countries. Int. Rev. Financ. Anal. 2014, 33, 281-288. [CrossRef]

20. Chen, C.Y.H. Does fear spill over? Asia Pac. J. Financ. Stud. 2014, 43, 465-491. [CrossRef]

21. Shu, H.C.; Chang, J.H. Spillovers of volatility index: Evidence from US, European, and Asian stock markets. Appl. Econ. 2019, 51, 2070-2083. [CrossRef]

22. Baker, S.R.; Bloom, N.; Davis, S.J. Measuring economic policy uncertainty. Q. J. Econ. 2016, 131, $1593-1636$. [CrossRef]

23. Gabauer, D.; Gupta, R. On the transmission mechanism of country-specific and international economic uncertainty spillovers: Evidence from a TVP-VAR connectedness decomposition approach. Econ. Lett. 2018, 171, 63-71. [CrossRef]

24. Antonakakis, N.; Gabauer, D.; Gupta, R.; Plakandaras, V. Dynamic connectedness of uncertainty across developed economies: A time-varying approach. Econ. Lett. 2018, 166, 63-75. [CrossRef]

25. Antonakakis, N.; Gabauer, D.; Gupta, R. International monetary policy spillovers: Evidence from a time-varying parameter vector autoregression. Int. Rev. Financ. Anal. 2019, 65, 101382. [CrossRef] 
26. Tsai, I.C. The source of global stock market risk: A viewpoint of economic policy uncertainty. Econ. Model. 2017, 60, 122-131. [CrossRef]

27. Chinn, M.D.; Ito, H. A new measure of financial openness. J. Comp. Policy Anal. 2008, 10, 309-322. [CrossRef]

28. Pesaran, M.H.; Shin, Y. Generalized impulse response analysis in linear multivariate models. Econ. Lett. 1998, 58, 17-29.

29. Bracker, K.; Docking, D.S.; Koch, P.D. Economic determinants of evolution in international stock market integration. J. Empir. Financ. 1999, 6, 1-27. [CrossRef]

30. Walti, S. The macroeconomic determinants of stock market synchronization. J. Int. Bank. Law 2005, 11, 436-441.

31. Flavin, T.J.; Hurley, M.J.; Rousseau, F. Explaining stock market correlation: A gravity model approach. Manch. Sch. 2002, 70, 87-106. [CrossRef]

32. Georgiadis, G. Determinants of global spillovers from US monetary policy. J. Int. Money Financ. 2016, 67, 41-61. [CrossRef]

33. Whaley, R.E. The investor fear gauge. J. Portf. Manag. 2000, 26, 12-17. [CrossRef]

34. Bekaert, G.; Mehl, A. On the global financial market integration "swoosh" and the trilemma. J. Int. Money Financ. 2019, 94, 227-245. [CrossRef]

35. Fang, L.; Bessler, D.A. Is it China that leads the Asian stock market contagion in 2015? Appl. Econ. Lett. 2018, 25, 752-757. [CrossRef]

Publisher's Note: MDPI stays neutral with regard to jurisdictional claims in published maps and institutional affiliations.

(C) 2020 by the authors. Licensee MDPI, Basel, Switzerland. This article is an open access article distributed under the terms and conditions of the Creative Commons Attribution (CC BY) license (http://creativecommons.org/licenses/by/4.0/). 